\title{
AFSKEIDING, SKEURING EN ROEPING TOT \\ EENWORDING
}

\author{
Prof. L. Roeleveld, Univ. Durban-Westville
}

\section{Vraagstelling}

Is kerklike verdeeldheid wat tot splitsing van gemeentes en ontstaan van afsonderlike kerkverbande lei, afskeiding of skeuring in die lig van die norme deur die Heilige Skrif en Konfessie i.v.m. kerklike eenheid en verdeeldheid? Hoe lank is so 'n verdeeldheid wettig? ${ }^{1}$

Wat is skeuring?

Calvyn ${ }^{2}$ skryf: ,Ketters en scheurmakers worden zij genoemd, die door het maken van tweedracht de gemeenschap der kerk verbreken. Augustinus maakt het onderscheid dat de ketters door valse leerstukken de zuiverheid des geloofs verderven, maar de scheurmakers, soms ook bij gelijkheid van geloof, den band der gemeenschap verscheuren'. Die Nagmaalsfomulier wys op sondaars wat begeer om tweedrag, sektes en muitery in kerke en wêreldlike regeringe aan te rig.

Feenstra ${ }^{3}$ vermeld oor "skeuring”: „De belijdenis spreekt van sekten, die zich met den naam van kerk bedekken. Het schisma heeft zich van de Kerk des Heeren afgescheurd, of zij heeft nooit de eenheid met de Kerk gezocht. Het lichaam des Heeren mag niet gescheurd worden. De kinderen uit eenzelfde gezin mogen niet afzonderlijk gaan wonen. De Kerk is het huisgezin van Jezus Christus. Alleen dan mag men zich afscheiden, wanneer er deformatie is." Wat is afskeiding? (Vgl. NGb art. 27-29)

Moet die NGB histories net volgens die gevoelens van De Brès of ook volgens die gangbare kerklike of teologiese opvatting van sy tyd verklaar word? Of moet ons vra na wat die konfessie uit die Skrif wil naspreek?

Ek sluit my aan by die tweede opvatting. Wie met die Belydenis die dood wil ingaan, wil die Belydenis met die Woord van God ondersoek ${ }^{4}$. Die uitsluitlik historiese interpretasie van die Belydenis het 'n hoekpyler van die sinodokrasie geword en van 1905 af in Nederland tot verminking van art. 36 oor die amp van die owerheid gelei ${ }^{5}$. Ek aanvaar die klassiek-gereformeerde opvatting dat afskeiding van 'n valse kerk wettig en verplig is ${ }^{\circ}$.

Wat afskeiding eintlik inhou, tipeer Schilder in 1934 ": „Recht en plicht tot afscheiding is op het allernauwste aan elkaar verbonden .... De belijdenis erkent het ambt aller gelovigen .... Zodra een kerkelijk instituut ten aanzien van zijn rechtsinrichting op twee gedachten hinkt...., moét ieder zich afvragen welke van die twee lijnen hij volgen moet .... Wie aan de belijdenis trouw bleef, schond de reglementen, wie aan de reglementen trouw bleef, schond de belijdenis.... Tot het jus constitutum behoort ook de belijdenis, 
die inzake het kerkrecht geen angstvallig zwijgen bewaart, maar zijn grondbeginselen opneemt in den geloofsinhoud. En nu verweet men aan de ,separatisten', dat $z i j$ in strijd kwamen met het geldend recht. Dat verwijt is echter zinloos, omdat zij, die het uitbrachten, of inbrengen, evenzeer ermede in strijd waren, en komen.... Op zichzelf .... bestaat er geen recht van scheiding in de kerk .... Niet Elia pretendeert een „recht" van afscheiding, maar Achab voltrekt de daad van Afscheiding.... Scheidde Elia zich af, toen hij het instituut van den Baälsdienst metterdaad weerstond? Neen, door het valse instituut uitgeworpen, scheidden de afgescheidenen zich daarvan, zij scheidden zicht niet van de kerk af .... de invoering der reglementen en der nieuwe proponentsformule zonder gelijktijdige terzijdestelling van de oude belijdenisgeschriften had een $\mathrm{zg}$. collisie van plichten geschapen."

\section{Regsaspekte van 'n gemeentesplitsing in Katwijk, Nederland}

Die GK (Vrijgemaakt) Katwijk het in 1961 in twee groepe uiteengeval. Buitestaanders, waaronder die geregshowe, kon moeilik beslis of daar sprake was van skeuring of afskeiding as wettige daad tot behoud van die eenheid van geloof en kerkregering ${ }^{8}$. Toe besware teen die bevestiging van 'n ouderling (art. 22 DKO) in Januarie 1961 ingekom het, het die stemme op 25 Januarie gestaak en twee lede het met verlof vertrek. Daarna is met die stem van 'n diaken wat na die vergadering teruggekeer het, besluit om die bevestiging wel te laat plaasvind. Revisie van die besluit kon nie verkry word nie omdat die predikant weier om die voorstel te laat dien. Drie lede waaronder die predikant verlaat die vergadering, terwyl die orige vier aangaan en besluit op 27 Januarie om die bevestiging nie te laat deurgaan nie, die predikant voorlopig te skors totdat die klassis oor die sake beslis het. Die volgende dag, Sondag 29 Januarie 1961, voor die erediens is die besluit van die vier aan die gemeente meegedeel en dat hulle om opskudding te vermy die erediens elders sal gaan hou. Die vier met 'n meerderheid gemeentelede het die kerkgebou verlaat; die predikant en die res het hul eie kerkdiens gehou en die ouderling is bevestig.

Na die gebeurtenisse op 29 Januarie 1961 het elke groep sy eie weg gegaan. Die meerdere vergaderinge het hul met die geskil besig gehou. Hul het die kerk wat deur die predikant en die ander twee kerkraadslede verteenwoordig is, in die kerkverband aanvaar. Albei groepe het die kerkgebou gesamentlik en om beurte gebruik. Die predikant het in die pastorie bly woon en sy groep van, drie' het nie bygedra tot die rente en delging van die verband op en onderhoud van die gebou nie.

Die kerk van die groep van "vier", wat intussen bekend geword het as „vrygemaaktes buite verband", het die groep van „drie" tien jaar na die konflik gedagvaar en op die goedere van die kerk voor die skeuring aanspraak gemaak of as alternatief medebeheer gevra.

In die daaropvolgende hofsake het geeneen van die partye die oorsaak vir die geskil op geloofsoortuiging of kerkregtelike 
opvattings gegrond nie. Hulle het van die DKO uitgegaan ${ }^{9}$.

Die Haagse Regbank het op 15 Junie 1971 die kerk o.l.v. van vier tot die alleen-eienaar verklaar kragtens die meerderheidstem op die vergadering van 27 Januarie 1961. Die Haagse Geregshof het op 18 April 1973 weer die uitspraak vernietig en die goedere toegewys aan die kerk van die drie kragtens die meerderheidsbesluit van 25 Januarie 1961. Die ander groep het hulle vrywillig onttrek en handelinge van die groep van vier was eiemagtig en onregmatig, en het nie gesteun op 'n besluit wat deur 'n bevoegde kerklike orgaan geneem is nie.

Die saak is daarna voorgelê aan die Hoge Raad wat net oor toepassing van die Nederlandse reg en nie oor kerkreg as sodanig oordeel nie. Hy beslis op 22 April 1974 dat die besluite van 25 en 27 Januarie 1961, geldig of nie, wel van belang kan wees vir die beoordeling van die gedrag van partye voor die skeuring, maar die Hoge Raad ${ }^{10}$ beslis in 1974 dat uitgemaak moet word of een party hom doelbewus wou losmaak van die ander party om as 'n selfstandige gemeente sy eie weg te gaan, anders kan die goedere van die oorspronklike regspersoon mede-eiendom van albei gemeentes word. Die Geregshof in Amsterdam konstateer in sy beslissing van 4 April 1975 dat die situasie wat op 29 Januarie 1961 ontstaan het, uitgangspunt vir die ondersoek is. Die hof stel $0 . m$. vas dat die , die vier' na die datum geweier het om met, die drie' te vergader. Uit hulle optrede blyk hul wil om hul los te maak. Dieselfde geld vir , die drie' wat nie volgens art. 37 'n vergadering laat byeenroep het nie, maar afsonderlik as kerkraad en in kerklike aktiwiteite voortgegaan het. Omdat albei partye gelyklik die wil gehad het om as ' $n$ selfstandige gemeente voort te bestaan en dic; wil in dade geopenbaar is, behoort die goedere van die oorspronklike gemeente aan hul in mede-eiendom.

\section{Beoordeling van die regterlike beslissings}

1. Kerklike twiste is op sigself betreurenswaardig, te meer wanneer regters uitmaak dat dit om persone en nie om beginsels gaan nie. Ek glo dat die Hoge Raad in teenstelling tot die laer howe die juiste norm vir beoordeling gewys het. Die meningsverskil omtrent bevestiging van 'n ouderling al of nie het geen regstreekse betrekking op die uiteengaan van die partye gehad nie. Die hardnekkige en onversoenlike gedrag van die partye op en na 29 Januarie 1978 , het volgens die howe die breuk veroorsaak.

2. Die Hoge Raad het sy leer uit die vorige eeu gehandhaaf dat in geval van gemeenteskeuring die regsposisie uit die gedrag van die partye uitgemaak word ${ }^{11}$. Dit mag vreemd lyk dat een gemeente sonder 'n uitdruklike besluit as twee gemeentes voortleef met medeeienaarskap van die goedere. Dit is op regsgronde die enigste moontlike konklusie op sterkte van die sogenaamde konversieleer, nl., dat 'n nietige regshandeling 'n geldige word wanneer dit buite twyfel vasstaan dat die betrokke partye dit wou gehad het ${ }^{12}$. Kerkverandering sou alleen betoog kon word as bewerings van valse leer of ander kerkreg gemaak was. Hier was dus geen sprake van afskei- 
ding of skeuring in konfessionele sin soos in die hofsake na aanleiding van die Vrymaking in 1944 nie.

3. Die beginsel van mede-eiendom is heeltemal in ooreenstemming met die Romeins-Hollandse reg. Die Hoge Raad van Holland en Zeeland het in besitsgeskille, waarin die bewys van albei kante ewe sterk was, die saak gelyklik onder die partye verdeel ${ }^{13}$. Ek meen dat in die geval van gemeentesplitsing, waarin 'n hof hom van 'n oordeel weerhou, die goedere in verhouding tot die ledetal verdeel behoort te word ${ }^{14}$. In die Katwijksaak het die howe die punt nie beslis nie.

4. As kritiek op die beslissing van die Hoge Raad is o.m. beweer ${ }^{10}$ dat rusie tussen twee groepe binne dieselfde regspersoon, nie van regsweë mede-eiendom kan teweegbring nie ${ }^{16}$.

Ek glo dat die kritiek ongegrond is. Die Hoge Raad het inteendeel daarvan uitgegaan dat die rusie in die regspersoon nie beslissend was nie, want hy het geoordeel dat die besluite omtrent die bevestiging al of nie van die ouderling irrelevant was vir die gemeentesplitsing. Hy kon egter nie ignoreer dat, soos Oldenhuis dit stel ${ }^{17}$, na die kruitdamp opgeklaar het, daar twee gemeentes uit die stryd te voorskyn gekom het nie wat albei pretendeer om die oorspronklike regspersoon voort te sit.

Die Romeinse, nog die Nederlandse reg vẹrbied dat 'n regspersoon hom in meer as een regspersoon verdeel of dat twee tot een verenig nie. Net so goed as die reg erken dat 'n gemeente as regspersoon sonder formaliteite kan ontstaan deur die wil van persone wat hul van 'n kerk afskeur en so 'n nuwe regspersoon vorm ${ }^{18}$, so $k a n$ sonder ontbindingsbesluit 'n bestaande gemeente hom verdeel in twee gemeentes ${ }^{19}$. Die identiteit van die gemeentes is dat hul albei die oorspronklike gemeente voortsit, soos 'n rivier hom in twee strome kan splits. Ek beskou dit as ' $n$ buitengewone geval waarin art. 38 DKO nie voorsien nie. Dit staan wel 'n meerdere vergadering vry om of albei gemeentes as lid van die verband te aanvaar, of geen van beide of een van beide.

\section{Roeping tot eenwording}

Die verwyt van 'n splytswam in gereformeerde kerke maak 'n appèl op ons kerklike gewete. In Nederland en mutatis mutandis in Suid-Afrika is daarom in hoë mate aktueel. Die boodskap van K. Schilder uit $1939^{20}$ is daarom in Nederland en in SA aktueel:

"Tegenover de bedroevende pluraliteit der elkaar weersprekende kerkelijke instituten hebben we, instee van ze met of zonder pluriformiteitstheorie te vergoelijken, steeds weer te strijden. Wapen in dien strijd kan nimmer zijn het halsstarrig alleen maar wijzen op fouten van een voorgeslacht, of van een kring van tijdgenoten, die, zeg 15 jaar geleden...., zich misgrepen hebben, naar onze mening. Want hoezeer ook het napluizen van zulke fouten soms onvermijdelijk, en, àls 't heus uit-pluizen is, ook leerzaam moge zijn, het kan toch niet volstaan voor wie den Pinkstergeest in zijn opmars naar de eenheid der kerkelijke samenleving zoveel mogelijk 
bijhouden en Hem daarin dienstbaar wezen wil. Indien, om maar bij Nederland te blijven, morgen aan den dag de Ned. Herv. Kerk, ook al zou haar synode geen (wetenschappelijk ingedacht) oordeel willen geven over 1834 en 1886, voor de toekomst zich zou willen vastleggen op de gereformeerde belijdenis (en dùs ook kerkregering), dan zouden we dadelijk móeten samenleven. Van de Nederlandsche Chr. Ger. Kerk geldt hetzelfde tegenover de Geref. Kerken. Zoals tussen de kerk en haar afzonderlijke leden van den kant der kerk zelf de band nooit ontbonden mag worden (in de tucht) vanwege een eens begane zonde, doch alleen vanwege de hardnekkigheid in de zonde, zo kan ook de éne kerk nooit van de andere harerzijds gescheiden willen blijven vanwege een eens begane zonde, doch alleen vanwege hardnekkigheid in die zonde, vanwege het standvastig blijven bij wat verkeerd was, en het wederom voor eigen rekening nemen daarvan. Dit geldt te meer, omdat in het eerste geval (kerk tegenover individueel kerklid) het kerklid dezelfde bleef, terwijl in het tweede geval (kerk tegenover kerk) de groepen na 15, 100 jaar, enz. ten dele of algeheel verdwenen zijn. Van de Ned. Herv. Kerk van heden is niemand aansprakelijk voor de zonden van 1834; de vraag is slechts, of de hervormde synode thans zou willen terugkeren tot de belijdenis. Van de in een tot leertucht besluitende synode aanwezige leden zijn na enkele jaren reeds velen gestorven, emeritus geworden, niet meer gedeputeerd. Bovendien bestaat die synode niet meer. .... Laten onder de ouderen over en weer bezwaren zijn tegen (vroeger) gepleegde handelingen, maar niet de handelingen van eertijds, doch de houding van heden beslist. Tot de goede houding over en weer nu behoort $66 \mathrm{k}$ het beven voor het Schriftwoord, dat de zoon niet zal dragen de ongerechtigheid der vaderen. Met elke volgende generatie moet men om Christus' wil willen spreken, teneinde de situatie opnieuw op te nemen.... Een secte is een secte; maar de kerk, die niet de secte wil oproepen tot bekeren, wordt sectarisch: zij wil niet samenbinden. Een schisma is een schisma; maar wie degenen loslaat, die hij zelf schismatiek noemt, wordt zelf schismatiek: hij wil niet samenbinden.... Daarentegen zal elk, die de gereformeerde belijdenis in dezen wèl handhaaft, en derhalve aanvaardt, dat de Geest Gods wel degelijk zijn stroom wil laten lopen door de bedding van het wettig kerkinstituut, dan ook altijd door druk werk hebben.

Hij zal bedenken, dat de stroom wel een ding is van den onvoltooid tegenwoordigen tijd, doch dat een bepaald instituut deels er een is vàn den voltooid tegenwoordigen tijd (inzoverre het $\mathrm{nl}$. zich heeft vastgelegd in formulieren, practijken, kerkenordeningen). En nu zal dit zijn grote zorg moeten zijn: dat, zizjn' instituut (voltooid tegenwoordigen tijd) toch steeds $\mathrm{z} 6$ in den ónvoltooid tegenwoordigen tijd ,mee geven' moge met de kracht en de souvereiniteit van den beweeglijken stroom des Geestes, dat de bedding den stroom kan bijhouden, kan dienen, zich dagelijks weder door den stroom laat vormen, verbreden hier, verdiepen daar, vernauwen ginds." 


\section{VERWYSINGS}

1 Vgl. J. H. van Wyk, Mag die kerk skeur? In die Skriflig Junie 1971 48-75. Diskussie na aanleiding daarvan in In die Skriflig Junie 1971 deur G. P. L van der Linde 45-48, D. C. S. van der Merwe 48-50, B. Spoelstra 51-55; Voortgesette diskussie J. H. van Wyk In die Skriflig Junie 1972 51-53.

2 Johannes Calvijn, Institutie, vertaald deur Dr. A. Sizoo, Delft 1931 ,IV, II, 5.

3 J. G. Feenstra, Onze Geloofsbelijdenis, Kampen 1947 2e druk 381.

$4 \mathrm{Vgl}$. eerste sin teenw. tyd Art. 1 asook Art. $7 \mathrm{NGb}$; J. R Wiskerke, Lucerna Gereformeerd Interfacultair Tijdschrift Jaargang III 718-732: Wèl confessie, geen confictie; 782-806: Confessioneel, niet confessionalistisch.

5 Joh. Francke, De Kerk en het Sociale vraagstuk, Rotterdam $19542 \mathrm{e}$ druk Hoofdstuk 3 B II 158-199: De kerk en het sociale vraagstuk onder het aspect der belijdenis. Hy behandel daar uitvoerig die vraagstuk van uitleg en binding aan die belydenis van die kerk, waarby hy die opvatting van Kuyper en Polman bestry.

6 Die bewering dat Calvyn toegee dat daar by Rome ,nog kerke' is, is deur Schilder oortuigend weerlé. Sien sy Verzamelde Werken, De Kerk Afdeling III Goes $196518-130$.

7 K Schilder, Verzamelde Werken De Kerk Deel II Goes 1962 in die opstel uit 1934, Beginsel, recht en betekenis der Afscheiding' 102-115.

8 Gegewens ontleen aan Nederlandse Jurisprudentie 1977 737-759.

9 Die Prokureur-Generaal het in sy advies aan die Hoge Raad verwys na die teks van die Dordtse Kerkorde, soos dit te vinde is in die Groot Placaetboek, derde deel, 1683 p 464 en hy het die teks van dic arts 30-37 woordelik oorgeneem. Kyk Nederlandse Jurisprudentie $1977 \mathbf{7 4 5}$.

10 Kenlik gebruik die Hoge Raad die uitdrukking ,skeuring' in die betekenis van ,uiteengaan van die groepe' en ,afskeiding' in die sin van ,uittrede' uit 'n bestaande gemeente; dus nie in die streng konfessionele betekenis nie.

11 Die leer word in art. 3.2.4.1 ontwerp vir 'n nuwe Burgerlik Wetboek gekodifiseer.

12 Die regstoepassing word in art. 3.28 ontwerp vir 'n nuwe Burgerlik Wetboek vasgelê.

13 Simon van Leeuwen, Censura Forensis, Leiden 1741 2.1.29.35 slot. Kyk ook E. M. Meijers, Themis 1916 bl $187-216$ oor bemiddelende vonnisse.

14 L. Roeleveld, Gereformeerde Kerken in het Privaatrecht, Zeist 195814. F. T. Oldenhuis, Rechtsvinding van de burgerlijke rechter in kerkelijke conflicten, Groningen $197773-74$ sluit hom hierby aan. Hy stel in die voetnoot op bl. 74: ...., de goederen behoren verdeeld te worden naar verhouding van het ledental, waaruit beide groepen (rechtspersonen) bestaan ten tijde van de kerkbreuk. Een verdeling naar verhouding van het aantal kerkeraadsleden in beide groepen aanwezig ten tijde van de kerkscheuring, is niet juist. De kerkelijke goederen behoren aan de rechts. persoon; de rechtspersoon wordt gevormd door haar leden, niet door haar vertegenwoordigers.'

15 G. J. Scholten in 'n annotasie onder die gepubliseerde hofsake

16 Vgl die kritiek van Scholten met die opvatting van D. C. G. Fourie, Die Nederduitse Gereformeerde Kerk as Regspersoon in die Suid-Afrikaanse Privaatreg, Ongepubliseerde LLD proefskrif Potchefstroom 1973 277-279, 290: Gemeenteskeuring is 'n regtens rewolusionere daad. Die regsorde is geroepe om die interne verbandreg nie alleen te erken nie, maar ook te beskerm teen anargie en menslike willekeur. Vanweë die deurwerking van 
die sonde is dit die primer roeping van die staat om die goeie orde te verseker deur die verskeidenheid van botsende belange in die maatskaplike lewe deur vergelding te harmoniseer. Indien in 'n gemeente botsende belange na vore kom en die wolwe dreig om die kudde van Christus uiteen te jaag, moet die staatsgesag met die geregshof as een van sy organe, indien daartoe versoek, dié botsende belange deur middel van 'n afdwingbare beslissing harmoniseer. Die hof moet in sodanige geskille slegs 'n formele maatstaf aanle... Wie wens om af te skei moet vrywillig uittree met prysgawe van alle lidmaatregte en voorregte. Die meerderheid of die minderheid is irrelevant.... Kerkskeuring is regtens 'n rewolusionere daad waaraan die regsorde geen gevolg behoort te gee nie.

Ek (L.R.) stel my nie agter die woordgebruik van Fourie nie.

17 Oldenhuis t.a.p. 79.

$18 \mathrm{Vgl}$. my Gereformeerde Kerken in het Privaatrecht t.a.p. 24 31/32.

19 dito.

20 K. Schildren, Verzamelde Werken, De Kerk deel II t.a.p. 413/415. 